\title{
Status of the Ir and Ir/SiC coating development for the Athena optics
}

Svendsen, Sara; Ferreira, Desiree D. M.; Massahi, Sonny; Jafari, Atefeh; Gellert, Nis C.; Christensen, Finn E.; Henriksen, Peter L.; Vu, Lan M.; Jegers, Arne S.; Shortt, Brian

Total number of authors:

16

Published in:

Space Telescopes and Instrumentation 2020: Ultraviolet to Gamma Ray

Link to article, DOI:

$10.1117 / 12.2562430$

Publication date:

2020

Document Version

Publisher's PDF, also known as Version of record

Link back to DTU Orbit

Citation (APA):

Svendsen, S., Ferreira, D. D. M., Massahi, S., Jafari, A., Gellert, N. C., Christensen, F. E., Henriksen, P. L., Vu, L. M., Jegers, A. S., Shortt, B., Landgraf, B., Girou, D. A., Collon, M. J., Cibik, L., Handick, E., \& Krumrey, M. (2020). Status of the Ir and Ir/SiC coating development for the Athena optics. In J-W. A. den Herder, S. Nikzad, \& K. Nakazawa (Eds.), Space Telescopes and Instrumentation 2020: Ultraviolet to Gamma Ray (Vol. 11444). [114444K] SPIE - International Society for Optical Engineering. Proceedings of SPIE - The International Society for Optical Engineering https://doi.org/10.1117/12.2562430

\section{General rights}

Copyright and moral rights for the publications made accessible in the public portal are retained by the authors and/or other copyright owners and it is a condition of accessing publications that users recognise and abide by the legal requirements associated with these rights.

- Users may download and print one copy of any publication from the public portal for the purpose of private study or research.

- You may not further distribute the material or use it for any profit-making activity or commercial gain

- You may freely distribute the URL identifying the publication in the public portal 


\section{Status of the Ir and Ir/SiC coating development for the Athena optics}

Svendsen, Sara, Ferreira, Desiree D., Massahi, Sonny, Jafari, Atefeh, Gellert, Nis, et al.

Sara Svendsen, Desiree D. M. Ferreira, Sonny Massahi, Atefeh Jafari, Nis C. Gellert, Finn E. Christensen, Peter L. Henriksen, Lan M. Vu, Arne S. Jegers, Brian Shortt, Boris Landgraf, David A. Girou, Maximillien J. Collon, Levent Cibik, Evelyn Handick, Michael Krumrey, "Status of the Ir and Ir/SiC coating development for the Athena optics," Proc. SPIE 11444, Space Telescopes and Instrumentation 2020: Ultraviolet to Gamma Ray, 114444K (13 December 2020); doi: $10.1117 / 12.2562430$ 


\title{
Status of the Ir and $\mathrm{Ir} / \mathrm{SiC}$ coating development for the Athena optics
}

\author{
Sara Svendsen $^{\mathrm{a}}$, Desiree D. M. Ferreira ${ }^{\mathrm{a}}$, Sonny Massahi ${ }^{\mathrm{a}}$, Atefeh Jafari ${ }^{\mathrm{b}}{ }^{\mathrm{a}}$, Nis C. Gellert ${ }^{\mathrm{a}}$, \\ Finn E. Christensen ${ }^{a}$, Peter L. Henriksen ${ }^{a}$, Lan M. Vu ${ }^{\mathrm{a}}$, Arne 'S Jegers ${ }^{\mathrm{a}}$, Brian Shortt ${ }^{\mathrm{c}}$, Boris \\ Landgraf $^{\mathrm{d}}$, David A. Girou ${ }^{\mathrm{d}}$, Maximilien J. Collon ${ }^{\mathrm{d}}$, Levent Cibik ${ }^{\mathrm{e}}$, Evelyn Handick ${ }^{\mathrm{e}}$, and \\ Michael Krumrey \\ ${ }^{a}$ DTU Space, Technical University of Denmark, Elektrovej 327, 2800 Kgs. Lyngby, Denmark \\ ${ }^{\mathrm{b}}$ Deutsches Elektronen-Synchrotron (DESY), Notkestr. 85, 22607 Hamburg, Germany \\ ${ }^{\mathrm{c}}$ European Space Agency (ESTEC), Keplerlaan 1, 2200 AZ Noordwijk, Netherlands \\ d cosine Research BV, Oosteinde 36, 2361 HE Warmond, Netherlands \\ ${ }^{\text {e}}$ Physikalisch-Technische Bundesanstalt (PTB), Abbestr. 2-12, 10587 Berlin, Germany
}

\begin{abstract}
The mirror coatings for the Athena X-ray telescope assumes $\mathrm{Ir} / \mathrm{SiC}$ bilayer thin films as a baseline design. Adding the soft overcoat to the Ir X-ray mirror coatings for the Athena optics is used to improve the low energy performance necessary to achieve the telescope effective area requirements.

The Athena mirror is based on silicon pore optics technology, for which the manufacturing process involves a sequence of wet chemical and thermal post-coating treatments of the mirror plates. Establishing compatibility of the thin film material candidates following exposure to these processes is critical for the Athena mission since the specific coating quality will influence the performance of the X-ray telescope.

We present an investigation of $\mathrm{Ir}$ and $\mathrm{Ir} / \mathrm{SiC}$ thin films exposed to post-coating treatments based on coatings produced at DTU Space. The current status of the chemical procedures is presented with representative coatings from the Athena-dedicated coating facility.
\end{abstract}

Keywords: Athena, X-ray optics, thin film, iridium, silicon carbide, silicon pore optics

\section{INTRODUCTION}

The Advanced Telescope for High ENergy Astrophysics (Athena) telescope is selected as the next large class X-ray observatory of the European Space Agency (ESA) ${ }^{1}$. The mission will feature a single X-ray telescope with a focal length of $12 \mathrm{~m}$ and a mirror design based on the silicon pore optics (SPO) technology ${ }^{2-4}$.

Achieving the science cases for Athena requires excellent X-ray reflective mirror coatings. The coating design for the Athena mirrors is based on a bilayer structure of $10 \mathrm{~nm}$ iridium (Ir) with a soft overcoat material such as silicon carbide $(\mathrm{SiC})^{5,6}$. The design parameters of these bilayer thin films are optimized with respect to the telescope effective area in order to increase the performance at $1 \mathrm{keV}^{5,7-9}$.

Over the past years, the X-ray mirror coatings for Athena have been developed at the direct current (DC) magnetron sputtering facility at DTU Space ${ }^{5,6,10-14}$. The mirror coating production for Athena is now proceeding at the newly established Athena-dedicated coating facility located at cosine Research BV ${ }^{15}$. The qualification and characterization of representative coatings is carried out by DTU Space at the Technical University of Denmark. Demonstrating stability of thin films is critical to adapt any X-ray mirror coating design for the Athena telescope. Thin films may evolve over time due to e.g. surface oxidation and interlayer diffusion. Repeated XRR measurements of Ir single-layer and $\mathrm{Ir} / \mathrm{SiC}$ bilayer thin films produced at DTU Space have not indicated any degradation of the coatings up to 1.5 years after coating ${ }^{5,6,16,17}$. An investigation of SiC single-layer thin films produced at the Athena-dedicated coating facility using X-ray reflectometry (XRR) and X-ray photoelectron spectroscopy (XPS) measurements has however demonstrated oxidation of the surface region and hydrocarbon accumulation, leading to a gradual thickness increase of the film following exposure to air ${ }^{16}$.

Further author information - send correspondence to:

Sara Svendsen, e-mail: sasv@space.dtu.dk)

Space Telescopes and Instrumentation 2020: Ultraviolet to Gamma Ray, edited by Jan-Willem A. den Herder

Shouleh Nikzad, Kazuhiro Nakazawa, Proc. of SPIE Vol. 11444, 114444K · (c) 2020 SPIE

CCC code: $0277-786 \mathrm{X} / 20 / \$ 21 \cdot$ doi: $10.1117 / 12.2562430$

Proc. of SPIE Vol. 11444 114444K-1 
In addition to demonstrating intrinsic thin film stability over time, candidate mirror coatings investigated for Athena must be compatible with the process steps required for SPO stack production. This includes wet chemical exposures of coated mirror plates required for photolithographic lift-off and organic surface cleaning, followed by thermal annealing, suggested to improve bonding strength of SPO stacks ${ }^{18}$. Robustness to the annealing procedure was previously studied for Ir single-layers and $\mathrm{Ir} / \mathrm{B}_{4} \mathrm{C}$ bilayers produced at DTU Space ${ }^{5,6}$. This pilot study indicated that the $10 \mathrm{~nm}$ Ir film is robust to annealing but that $\mathrm{B}_{4} \mathrm{C}$ deposited in the DTU Space coating chamber is affected which is likely due to oxidation.

We present an investigation of the influence of process requirements for the manufacturing of SPO stacks on Ir single-layer and $\mathrm{Ir} / \mathrm{SiC}$ bilayer thin films coated at DTU Space. Since the specific thin film quality depends on the deposition facility, however, the work presented here is considered a demonstration of methodology serving as a prestudy to qualify the robustness of Ir single-layer and $\mathrm{Ir} / \mathrm{SiC}$ bilayer designs to these processes.

With the new Athena-dedicated coating machine now in operation, the further R\&D of mirror coatings for Athena takes place at this facility. Preliminary results on the robustness of Ir single-layer and Ir/SiC bilayer thin films coated at the new Athena-dedicated coating facility to the chemical processes are presented.

\section{EXPERIMENTAL METHODS}

The samples considered in this study include $10 \mathrm{~mm} \times 70 \mathrm{~mm} \times 0.75 \mathrm{~mm}$ double-side superpolished Si substrates, denoted witness samples, in addition to SPO plates measuring $65.7 \times 40.0 \mathrm{~mm}^{2}$ (Athena middle radius plates).

\subsection{Sample preparation}

The mirror coatings for the Athena telescope are produced by DC magnetron sputtering. The main part of this work considers samples with thin film deposition carried out in the coating chamber at DTU Space. Preliminary results on thin films produced at Athena-dedicated coating facility at cosine Research BV are presented to give the current status of chemical exposure of representative thin films.

Plasma cleaning prior to thin film deposition was implemented as a process step throughout the development of wet chemical procedures. Where indicated, witness samples coated at DTU Space were plasma cleaned using a PVA TePla 300 Plasma Asher (PA) at DTU Nanolab.

All SPO plates produced at the new Athena-dedicated coating facility were plasma cleaned prior to thin film deposition using the built-in inverse sputter etcher (ISE) unit ${ }^{19}$.

The effects of post-coating treatments were evaluated based on the following process descriptions. An untreated sample refers to a thin film prior to exposure to any treatment. All presented samples and their specific pre- and post-deposition treatments are listed in table 1.

\subsubsection{Post-coating chemical treatments}

Removal of the photolithographic patterning on coated SPO plates is carried out using an ultrasonic bath of dimethyl sulfoxide (DMSO) heated to $60{ }^{\circ} \mathrm{C}$ for 10 minutes.

The cleaning process uses a diluted Standard Clean 1 (SC-1) of the RCA procedure to remove organic surface contamination as well as to activate the $\mathrm{Si}$ surface for bonding. In the current process implementation, samples are treated in a solution of $\mathrm{NH}_{4} \mathrm{OH}, \mathrm{H}_{2} \mathrm{O}_{2}$ and DI water $(1: 1: 20)$ at $80{ }^{\circ} \mathrm{C}$ for 10 minutes.

\subsubsection{Post-coating thermal treatment}

Annealing was performed using a Lab Companion OV-11 vacuum oven at DTU Space. The annealing procedure was carried out in compliance with specifications provided by cosine Research BV by heating coated samples to $200{ }^{\circ} \mathrm{C}$ for 50 hours, including 2 hours of preheating. The annealing is performed in atmospheric conditions, and while the humidity level in the laboratory has not measured, it is expected to be in the range (55 \pm 15$) \%$. 
Table 1: List of single-layer and bilayer coated samples including the applied pre- and post-coating treatments. The thin films were deposited at DTU Space and at the Athena-dedicated coating facility (ACF).

\begin{tabular}{llccr}
\hline Sample & Coating & $\begin{array}{c}\text { Coating } \\
\text { facility }\end{array}$ & $\begin{array}{c}\text { Plasma } \\
\text { cleaning }\end{array}$ & $\begin{array}{r}\text { Post-coating } \\
\text { treatment }\end{array}$ \\
\hline si6520 & Ir single-layer & DTU & None & DMSO (DTU) \\
si6828 & Ir/SiC bilayer & DTU & None & None \\
si6832 & Ir/SiC bilayer & DTU & None & DMSO (DTU) \\
SPO 574-11 & Ir single-layer & DTU & None & DMSO (cosine) \\
SPO 574-10 & Ir single-layer & DTU & None & DMSO, SC-1 (cosine) \\
si6522 & Ir single-layer & DTU & None & DMSO, SC-1 (DTU) \\
si6541 & Ir single-layer & DTU & PA & DMSO, SC-1 (DTU) \\
si7017 & Ir/SiC bilayer & DTU & PA & None \\
si7021 & Ir/SiC bilayer & DTU & PA & $200{ }^{\circ}$ C for 50 hours \\
SPO 766-13 & Ir single-layer & ACF & ISE & DMSO; SC-1 (cosine) \\
SPO 772-09 & Ir single-layer & ACF & ISE & None \\
SPO 816-15 & Ir/SiC bilayer & ACF & ISE & DMSO; SC-1 (cosine) \\
SPO 667-12 & Ir/SiC bilayer & ACF & ISE & None \\
SPO 396-12 & Ir/SiC bilayer & ACF & ISE & DMSO; SC-1 (cosine) \\
SPO 440-06 & Ir/SiC bilayer & ACF & ISE & None \\
\hline
\end{tabular}

\subsection{X-ray reflectometry characterization}

Thin film characterization was primarily carried out using XRR to establish thin film parameters and to assess stability of performance. XRR measurements were fitted using the IMD software ${ }^{20}$.

\subsection{8 keV X-ray reflectometry at DTU Space and DTU Nanolab}

$8.048 \mathrm{keV}$ characterization of witness samples was performed at DTU Space. The system is equipped with a $\mathrm{Cu}$ source and uses an asymmetrically-cut Ge double-bounce monochromator tuned to the $\mathrm{Cu} \mathrm{K} \alpha_{1}$ line. Measurements were performed with an $\mathrm{Ar} / \mathrm{CH}_{4}$ gas-filled linear position sensitive detector. The beam shaping slit before the sample stage was set to $0.12 \times 3.0 \mathrm{~mm}^{2}$ (height $\times$ width). An instrumental angular resolution of $\theta_{\text {res }}=7$ millidegrees was assumed.

In addition, a Rigaku XRD SmartLab system in the cleanroom at DTU Nanolab was used for $8.048 \mathrm{keV}$ measurements. The setup is equipped with a $0.4 \times 8 \mathrm{~mm}^{2}$ focus $\mathrm{Cu} \mathrm{K} \alpha$ source and a $\mathrm{Ge}(220) \times 2$ monochromator. The measurements were carried out using parallel beam conditions and a D/teX Ultra 1D detector. The beam shaping slit was set to $0.12 \times 2.0 \mathrm{~mm}^{2}$ (height $\times$ width). An angular resolution of $\theta_{\text {res }}=1$ millidegrees is assumed for the system.

\subsubsection{The Low-Energy Reflectometer at DTU Space}

The Low-Energy X-ray Reflectometer (LEXR) adds capability for low-energy measurements at DTU Space X-ray facility which is critical for fast characterization of low-Z thin film materials. The system was custom-built for DTU Space by JJ X-ray with installation and final commissioning tests performed by the end of $2019^{21,22}$.

The system is operated in vacuum $\left(p<9 \cdot 10^{-6} \mathrm{mbar}\right)$, and features a $1.487 \mathrm{keV} \mathrm{Al} \mathrm{K \alpha}$ microfocus source $(0.15$ $\times 0.05 \mathrm{~mm}^{2}$ ). Samples were measured with a beamshaping slit size of $0.5 \times 2.0 \mathrm{~mm}^{2}$ (height $\times$ width). The slit before the detector was set to $3.0 \times 5.0 \mathrm{~mm}^{2}$. The angular resolution of the system is $\theta_{\text {res }}=7$ millidegrees.

\subsubsection{The Four-Crystal Monochromator beamline at BESSY II}

The Four-Crystal Monochromator (FCM) beamline at the PTB laboratory at BESSY II provides high-purity synchrotron radiation. The beamline is equipped with $\mathrm{Si}(111)$ and $\operatorname{InSB}(111)$ monochromator crystals, allowing for operation in a $1.75-10 \mathrm{keV}$ range with an energy resolution $<1 \mathrm{eV}^{23}$. The sample stage and detectors are positioned under ultra-high vacuum. The beam divergence is $<2 \mathrm{mrad}$ and $<0.3 \mathrm{mrad}$ in the horizontal and vertical planes, respectively. An instrumental angular resolution of $\theta_{\text {res }}=1$ millidegrees is assumed.

XRR measurements were performed in the energy range of $3.4-10 \mathrm{keV}$ at various grazing incidence angles with the $4.5 \times 4.5 \mathrm{~mm}^{2}$ GaP diode. $\theta-2 \theta$ angle scan measurements at fixed energies were performed using the $2.5 \times 0.3 \mathrm{~mm}^{2}$ (height $\times$ width) slit diode. 


\subsection{Atomic force microscopy}

The thin film surfaces were characterized using atomic force microscopy (AFM) and optical microscopy. AFM measurements were performed using a Bruker AFM Dimension Icon-Pt system at DTU Nanolab operated in PeakForce tapping mode with ScanAsyst enabled. Figure 1 shows the AFM measurement locations used for 1 $\times 1 \mu \mathrm{m}^{2}$ and $10 \times 10 \mu \mathrm{m}^{2}$ on SPOs samples within a few mm uncertainty.

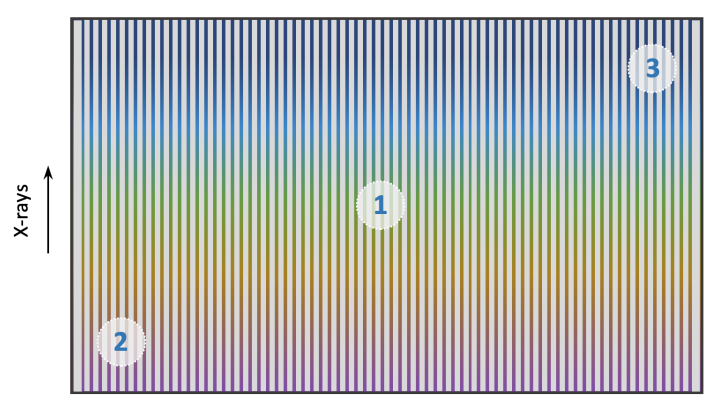

Figure 1: Illustration of the three spot areas on SPO plates measured with AFM. The arrow indicates the plate orientation and the beam direction used for XRR.

The AFM data was postprocessed in the Gwyddion software using a 3rd degree polynomial alignment of scan rows, followed by base flattening to correct for residual tilt ${ }^{24}$.

The Power Spectral Density (PSD) was derived from the AFM images to compare surface topographies and compute root mean square (RMS) surface roughnesses using the TOPO library for surface topography analysis ${ }^{25}$. The procedure calculates the PSD along the scanning direction and computes the average over all rows to obtain the 1D PSD in frequency space.

\section{RESULTS AND DISCUSSION}

The influence of the wet chemistry procedures was investigated on representative Ir single-layer and $\mathrm{Ir} / \mathrm{SiC}$ bilayer coatings produced at DTU Space. This prestudy was used to identify potential risk factors to the thin films.

Preliminary results on wet chemical compatibility of Ir single-layer and $\mathrm{Ir} / \mathrm{SiC}$ bilayers produced at the new Athena-dedicated coating facility are shown. Furthermore, the first study of annealed $\mathrm{Ir} / \mathrm{SiC}$ bilayers produced at DTU Space is presented.

\subsection{Compatibility with DMSO treatment for thin films prepared at DTU Space}

The compatibility of Ir single-layer and Ir/SiC bilayer coatings with the DMSO treatment was established based on samples produced at DTU Space. The samples were not plasma cleaned prior to coating. The treatment using DMSO was performed in the cleanroom at DTU Nanolab.

Figure 2 shows XRR measurements of an Ir single-layer sample (si6520) performed at the DTU Space $8.048 \mathrm{keV}$ reflectometer before and after exposure to DMSO. The measured reflectances are in agreement, indicating no impact on the coating roughness or thickness. These results support previous indications that Ir single-layer films produced at DTU Space are not affected by the photolithographic lift-off process using DMSO ${ }^{5}$.

Optical microscope images taken near the sample center shown in figure 3 suggest that the Ir surface is intact before and after exposure to DMSO. 


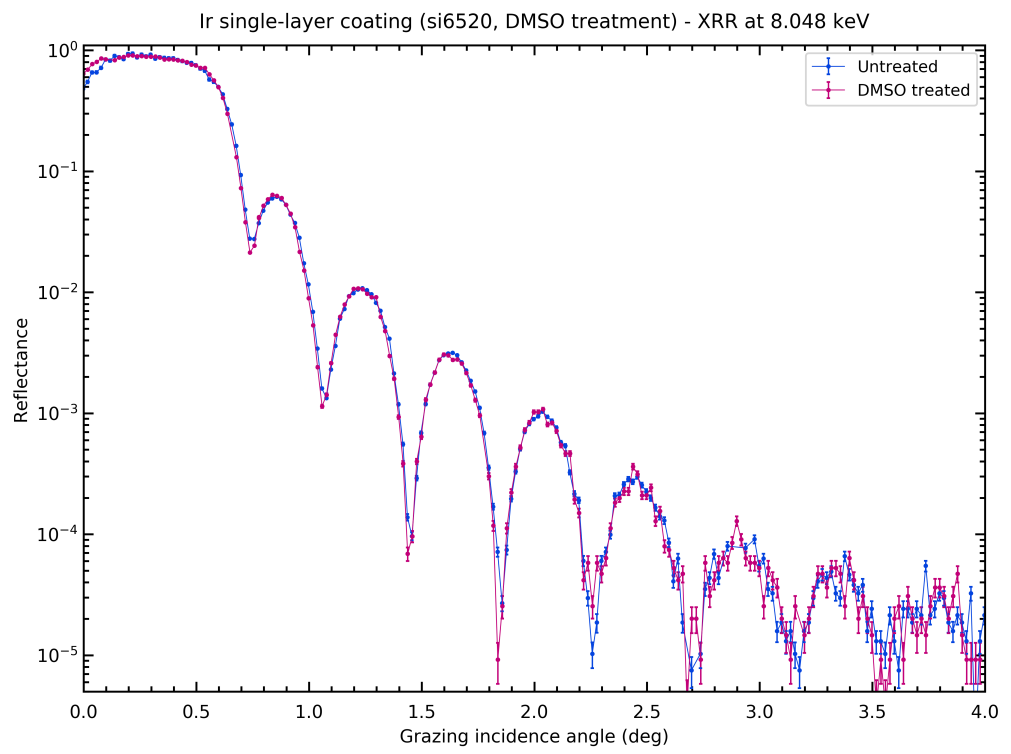

Figure 2: XRR at $8.048 \mathrm{keV}$ measured at DTU Space of Ir single-layer si6520 before and after DMSO treatment performed at DTU Space.
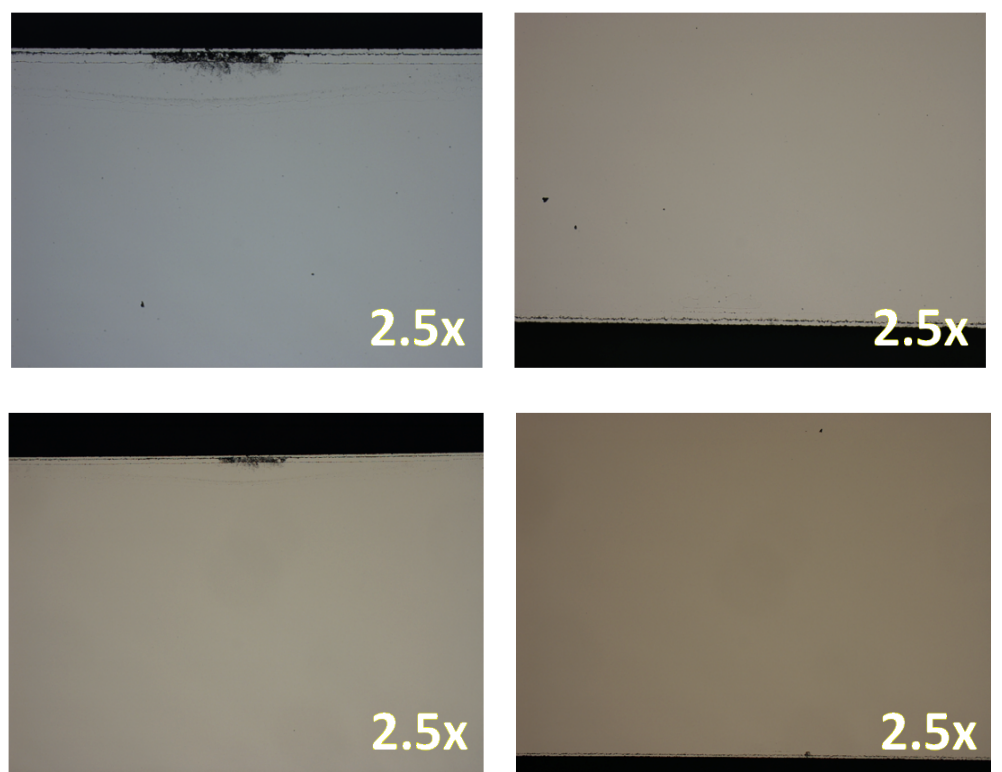

Figure 3: Microscope images at $2.5 \times$ magnification near the edges in the center of Ir single-layer si6520. Top images: no chemistry, untreated. Bottom images: after DMSO treatment.

The effect of DMSO on the SiC overcoat was evaluated by comparing 0.6 degree measurements performed at the laboratory of PTB at BESSY II of Ir/SiC bilayer samples. A beam shaping slit of $0.2 \times 0.6 \mathrm{~mm}^{2}(\mathrm{vertical}$ $\times$ horizontal) was used. Figure 4 shows measurements of the DMSO treated si6832 compared to the untreated reference si6828. The models illustrate the reflectance of an Ir-only layer (10 nm) and a Ir/SiC bilayer (10 nm/6 $\mathrm{nm}$ ) of which the latter is consistent with the XRR data. 
The measurements are in agreement within the assumed $1 \%$ errorbars. The small discrepancy above $\sim 8.5 \mathrm{keV}$ could be attributed to sample misalignment or coating non-uniformity. This comparison of untreated and DMSO treated $\mathrm{Ir} / \mathrm{SiC}$ bilayers suggests that $\mathrm{SiC}$ deposited in the DTU chamber is robust to DMSO treatment.

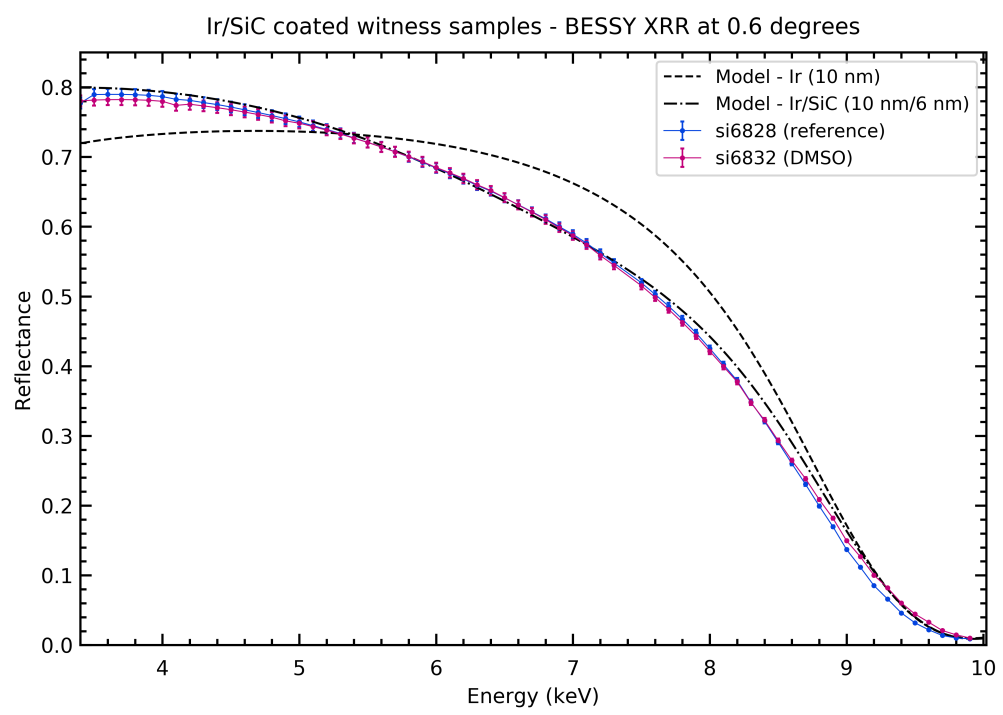

Figure 4: XRR at 0.6 degrees measured at the laboratory of PTB at BESSY II of Ir/SiC bilayer coated witness samples si6828 (no chemistry, untreated) and si6832 (DMSO treated). The simulated models show the reflectance for a 10 nm Ir single-layer, and a bilayer with $10 \mathrm{~nm}$ Ir and a $6 \mathrm{~nm} \mathrm{SiC} \mathrm{overcoat.} \mathrm{All} \mathrm{roughnesses} \mathrm{were} \mathrm{set} \mathrm{to} 0.3 \mathrm{~nm}$.

\subsection{Compatibility with SC-1 treatment for thin films prepared at DTU Space}

The robustness to SC-1 was investigated based on a set of photoresist patterned SPO plates coated with $10 \mathrm{~nm}$ Ir at DTU Space. The samples were subsequently chemistry treated by cosine Research BV. SPO 574-11 was exposed to DMSO while SPO 574-10 was lifted and cleaned using DMSO and SC-1.

XRR measurements of the two samples at $8.048 \mathrm{keV}$ and at 0.6 degrees performed 2 months after coating at the laboratory of PTB at BESSY II are shown in figure 5. A beam shaping slit size of $0.26 \times 0.8 \mathrm{~mm}^{2}$ was used. These results demonstrate agreement between the samples which suggests that Ir-only is not affected by either DMSO or SC-1. The observed difference below $8 \mathrm{keV}$ between 0.6 degrees measurements is attributed to variations in a hydrocarbon overlayer.

Table 2: Best fit parameters to XRR measurements of Ir single-layer SPO 574-10 (DMSO and SC-1) and SPO 574-11 (DMSO). ${ }^{a}$ denotes a fixed parameter. Parameters marked with ${ }^{b}$ were fitted as a coupled parameter. The $\chi^{2}$ is weighted by the reflectance.

\begin{tabular}{|c|c|c|c|c|c|c|c|}
\hline \multirow{2}{*}{ Sample } & \multirow{2}{*}{ Measurement } & \multicolumn{2}{|c|}{$\mathrm{COH}$} & \multicolumn{2}{|c|}{ Ir } & \multirow{2}{*}{$\frac{\mathrm{SiO}_{2} \text { (substrate) }}{\sigma(\mathrm{nm})}$} & \multirow{2}{*}{$\chi^{2} / \mathrm{ndf}$} \\
\hline & & $z(\mathrm{~nm})$ & $\sigma(\mathrm{nm})$ & $z(\mathrm{~nm})$ & $\sigma(\mathrm{nm})$ & & \\
\hline SPO 574-10 (DMSO, SC-1) & $8.048 \mathrm{keV}$ & - & - & 10.41 & 0.48 & 0.38 & $1.183 / 297$ \\
\hline SPO 574-10 (DMSO, SC-1) & $0.6 \mathrm{deg}$ & - & - & 10.97 & 0.72 & 1.71 & $0.007785 / 55$ \\
\hline SPO 574-10 (DMSO, SC-1) & $0.6 \mathrm{deg}$ & 2.45 & $0.68^{b}$ & 10.46 & $0.68^{b}$ & 1.28 & $0.002260 / 54$ \\
\hline SPO 574-11 (DMSO) & $8.048 \mathrm{keV}$ & - & - & 10.44 & 0.47 & 0.37 & $1.096 / 297$ \\
\hline SPO 574-11 (DMSO) & $0.6 \mathrm{deg}$ & - & - & 10.41 & 0.48 & 0.38 & $0.006788 / 55$ \\
\hline SPO 574-11 (DMSO) & $0.6 \mathrm{deg}$ & 2.54 & $0.75^{b}$ & 10.64 & $0.75^{b}$ & 1.17 & $0.001263 / 54$ \\
\hline
\end{tabular}



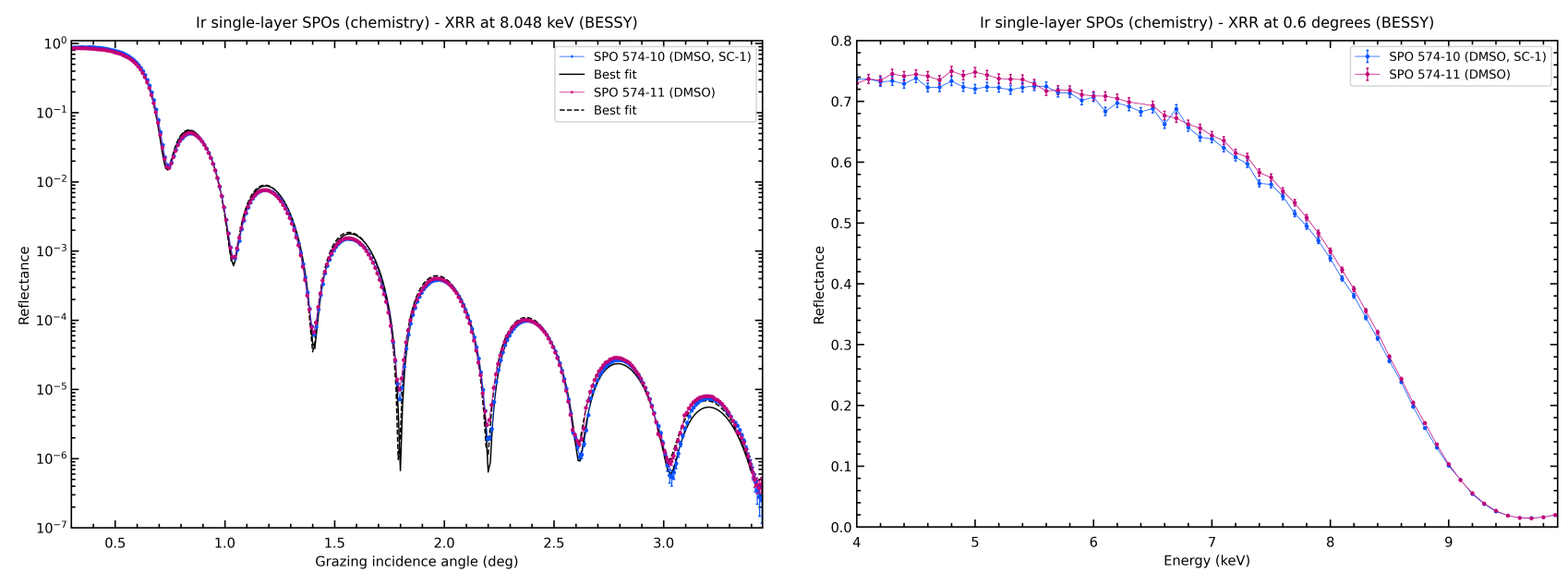

Figure 5: BESSY XRR measurements at $8.048 \mathrm{keV}$ and at 0.6 degrees comparing Ir single-layer SPO 574-10 (DMSO and SC-1) and SPO 574-11 (DMSO).
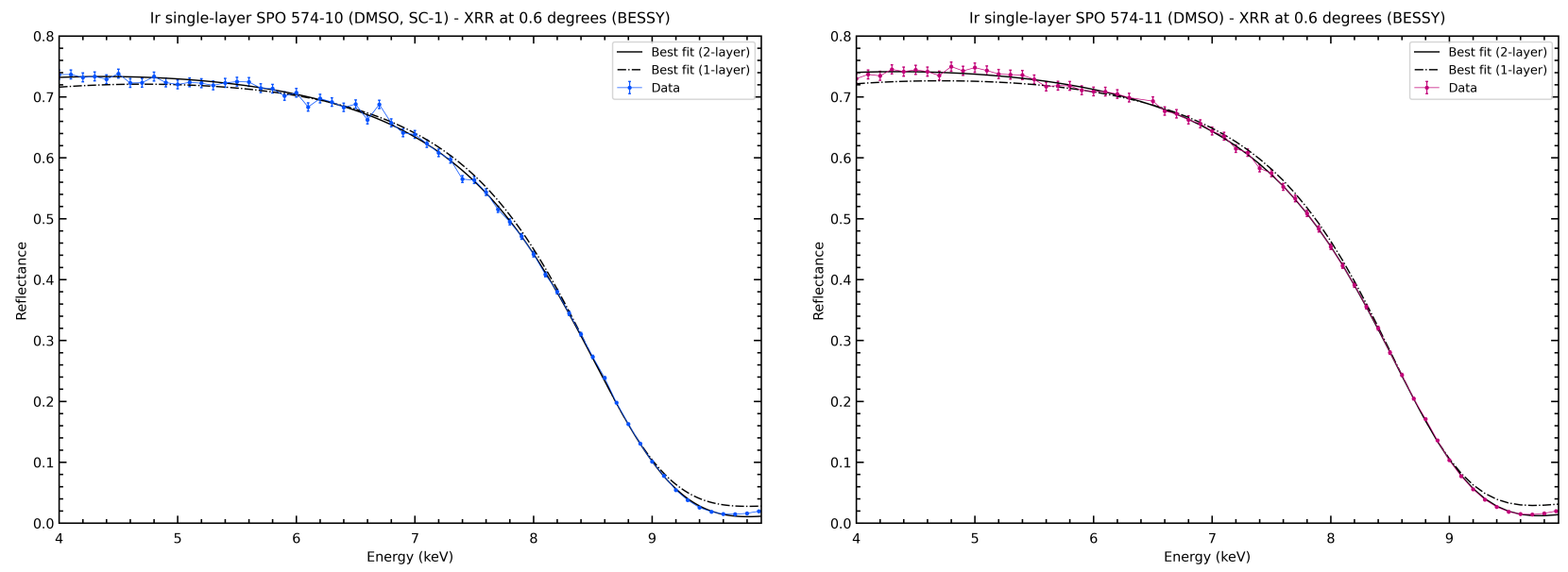

Figure 6: BESSY XRR at 0.6 degrees and best fits of Ir single-layer SPO 574-10 (DMSO and SC-1) and SPO 574-11 (DMSO).

The presence of a hydrocarbon overlayer is demonstrated by comparing fits to the 0.6 degree data using a 1-layer Ir-only model, as well as a 2-layer model which considers a hydrocarbon overlayer (assumed as a COH compound) with a fixed density of $1.00 \mathrm{~g} / \mathrm{cm}^{3}$. The XRR data and best fits given the two models are shown in figure 6 . The best fit parameters are presented in table 2 .

From follow-up measurements performed 29 months after coating at the laboratory of PTB at BESSY II, we observe no long-term evolution of Ir after DMSO and SC-1 treatment. Figure 7 (left) shows the agreement between $8.048 \mathrm{keV}$ measurements of the two samples by comparing data from 2 and 29 months after coating. The measurements shown in figure 7 (right) at different grazing incidence angles are in agreement, aside from an apparent shift at 0.6 degrees due to sample misalignment. Note that these measurements were performed with a different beam shaping slit size setting of $0.2 \times 0.35 \mathrm{~mm}^{2}$ compared to the first measurement campaign. 

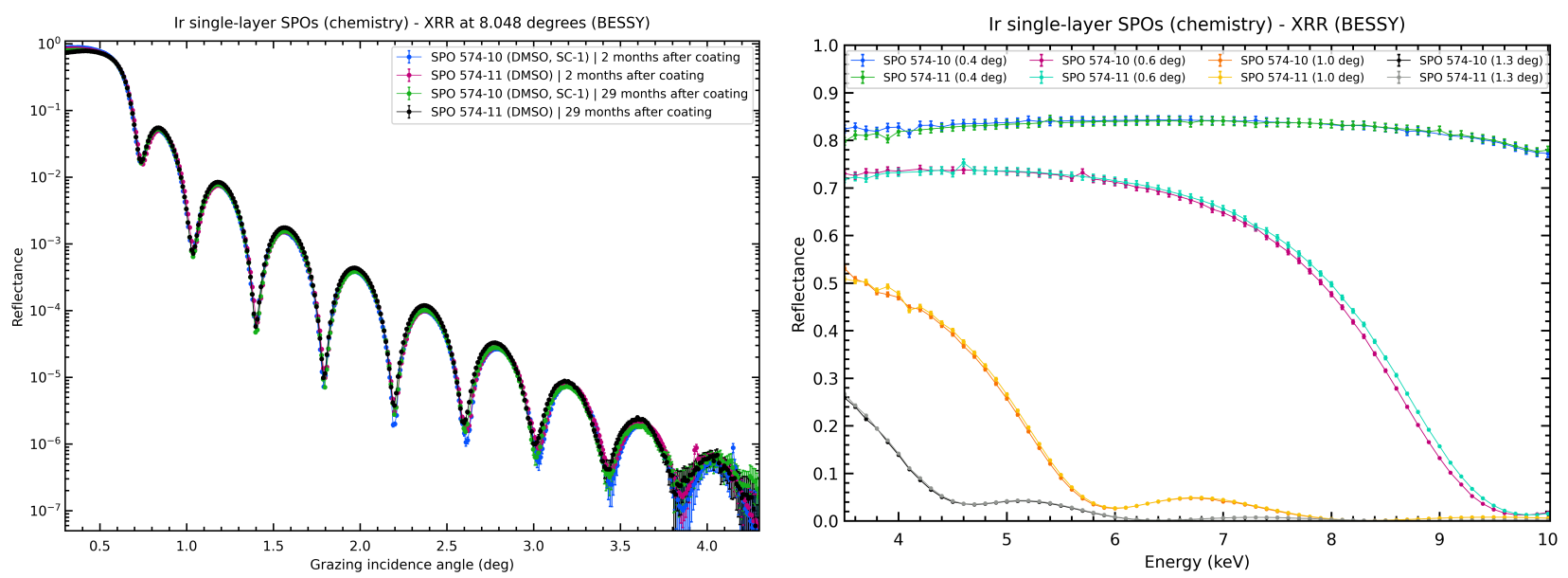

Figure 7: XRR measurements from the laboratory of PTB at BESSY II of Ir single-layer SPO 574-10 (DMSO and SC-1) and SPO 574-11 (DMSO). Left: $8.048 \mathrm{keV}$ data measured 2 and 29 months after coating. Right: Measurements at $0.4,0.6,1.0$ and 1.3 degrees of the two samples performed 29 months after coating. The discrepancy between 0.6 degree measurements is due to a minor sample misalignment.

The AFM images presented in figures 8-9 demonstrate the high surface quality of Ir coated SPO samples, aside from the presence of particulate surface contamination.

RMS roughnesses were computed from the AFM measurements by integrating the derived 1D PSDs over the frequency ranges shown in figure 10. The RMS roughnesses presented are in table 3, with average values between $0.25-0.31 \mathrm{~nm}$. These measurements indicate that the Ir surface quality is unaffected by the DMSO and SC-1 exposures.

Table 3: Derived RMS roughnesses from AFM scans of Ir single-layer SPO 574-11 (DMSO) and SPO 574-10 (DMSO, SC-1).

\begin{tabular}{lccc}
\hline Position & $\begin{array}{c}\text { Scan size } \\
\left(\mu \mathrm{m}^{2}\right)\end{array}$ & $\begin{array}{c}\text { SPO 574-11 } \\
\sigma(\mathrm{nm})\end{array}$ & $\begin{array}{c}\text { SPO 574-10 } \\
\sigma(\mathrm{nm})\end{array}$ \\
\hline Spot 1 & $1 \times 1$ & 0.29 & 0.23 \\
Spot 1 & $10 \times 10$ & 0.30 & 0.26 \\
Average $\sigma$ & & $\mathbf{0 . 3 0}$ & $\mathbf{0 . 2 5}$ \\
\hline Spot 2 & $1 \times 1$ & 0.29 & 0.30 \\
Spot 2 & $10 \times 10$ & 0.33 & 0.25 \\
Average $\sigma$ & & $\mathbf{0 . 3 1}$ & $\mathbf{0 . 2 8}$ \\
\hline Spot 3 & $1 \times 1$ & 0.22 & 0.25 \\
Spot 3 & $10 \times 10$ & 0.28 & 0.25 \\
Average $\sigma$ & & $\mathbf{0 . 2 5}$ & $\mathbf{0 . 2 5}$ \\
\hline
\end{tabular}



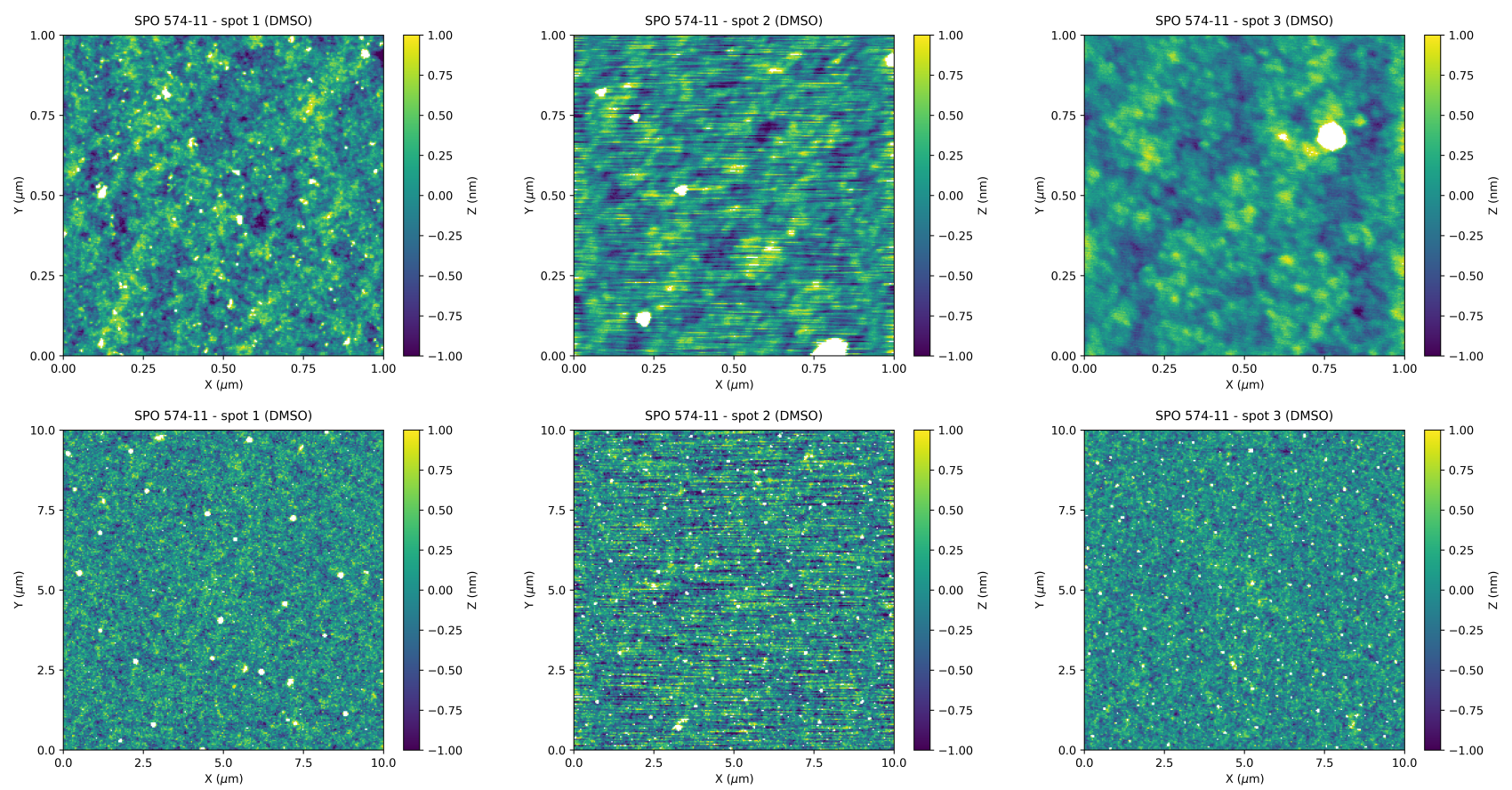

Figure 8: AFM images measured at three spots on the DMSO treated Ir single-layer SPO $\mathbf{5 7 4 - 1 1}$ for $1 \times 1 \mu \mathrm{m}^{2}$ (top) and $10 \times 10 \mu \mathrm{m}^{2}$ (bottom) scan areas.
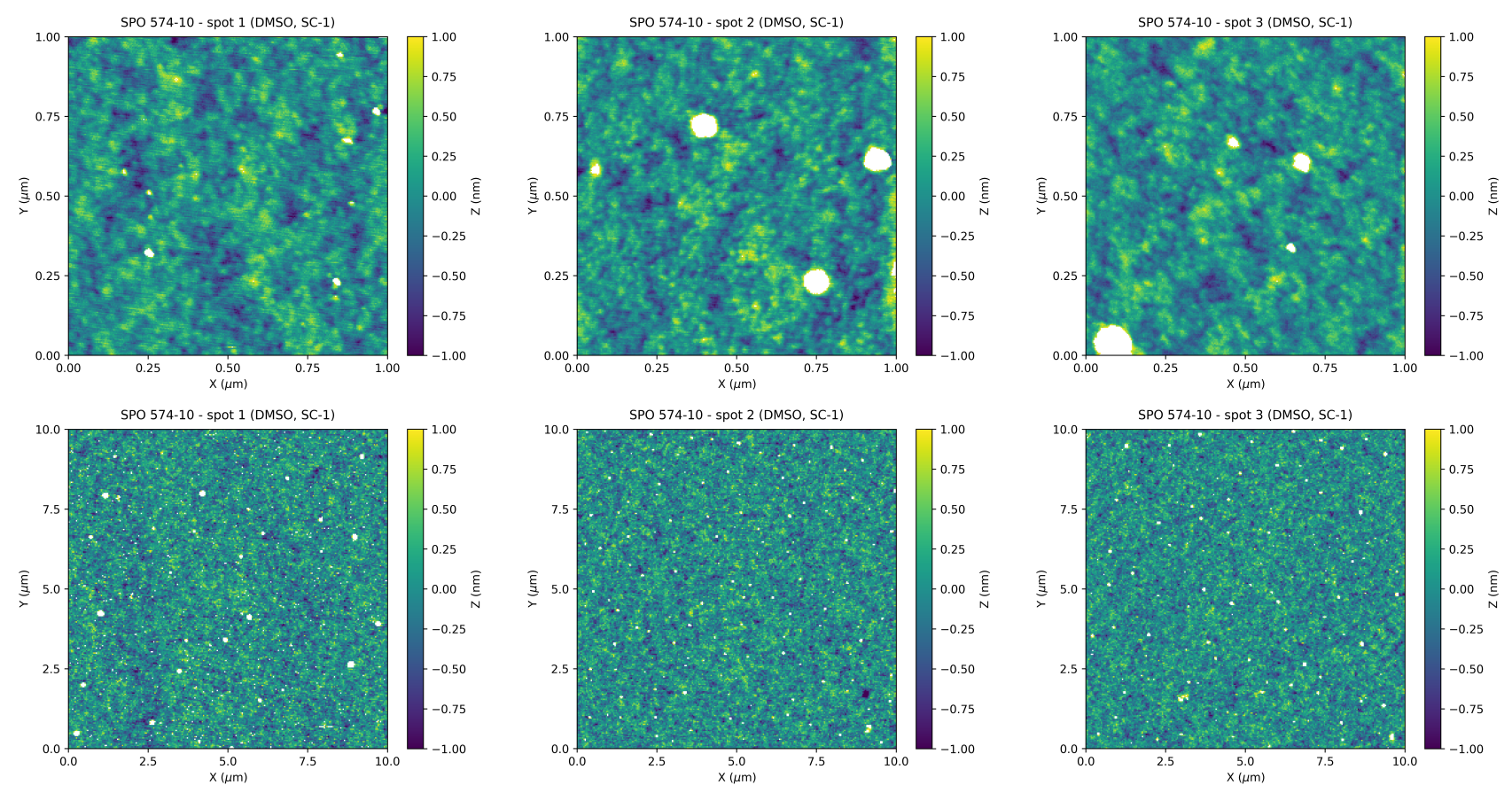

Figure 9: AFM images measured at three spots on the DMSO and SC-1 treated Ir single-layer SPO $\mathbf{5 7 4 - 1 0}$ for $1 \times 1$ $\mu \mathrm{m}^{2}$ (top) and $10 \times 10 \mu \mathrm{m}^{2}$ (bottom) scan areas. 

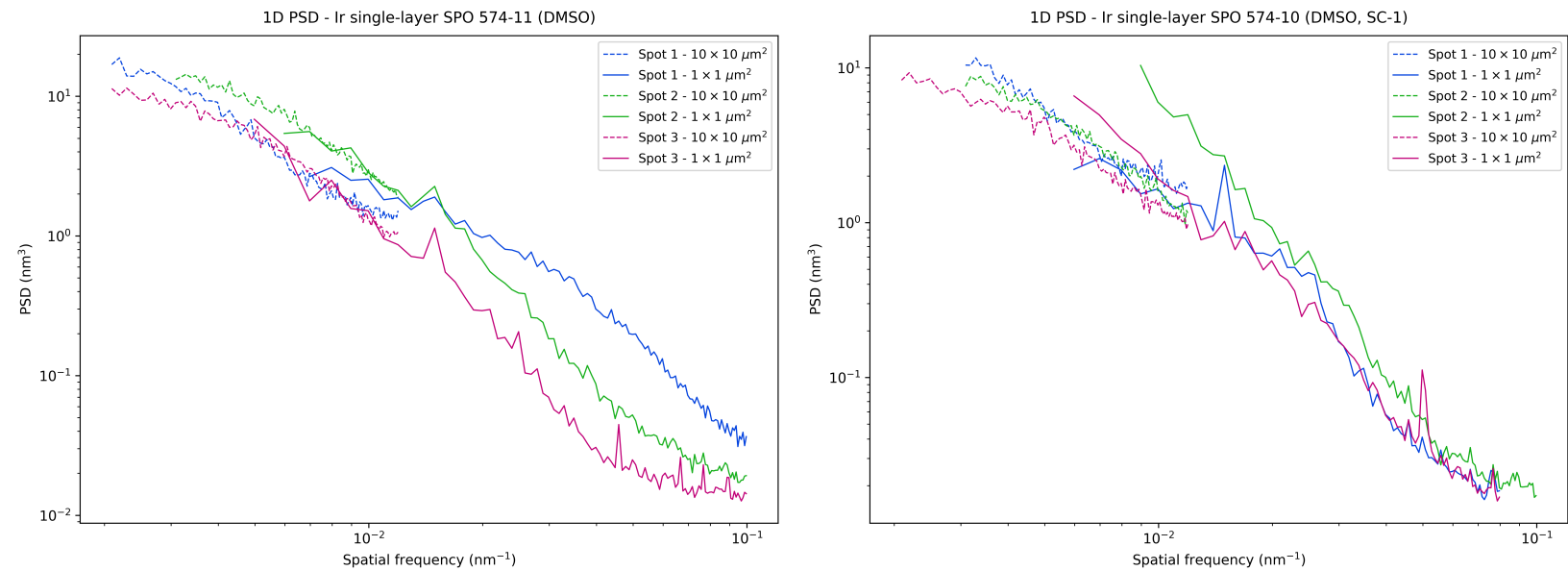

Figure 10: PSDs derived from AFM measurements of Ir single-layer SPO 574-11 (DMSO) and SPO 574-10 (DMSO, SC-1).

Optical microscope images of the two SPOs are shown in figures 11 and 12. The images of SPO 574-10 reveal some occurences of pinholes and delamination following the SC-1 treatment. The damage is sparse and mainly concentrated along the sample edges.
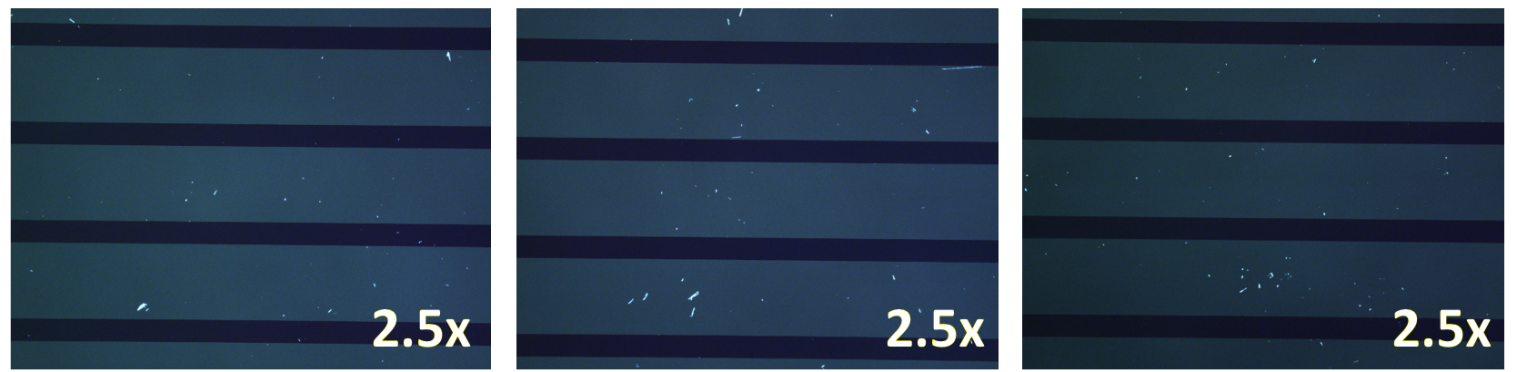

Figure 11: Microscope images of the DMSO treated Ir single-layer SPO 574-11. From left to right: top center, middle center, and bottom center.
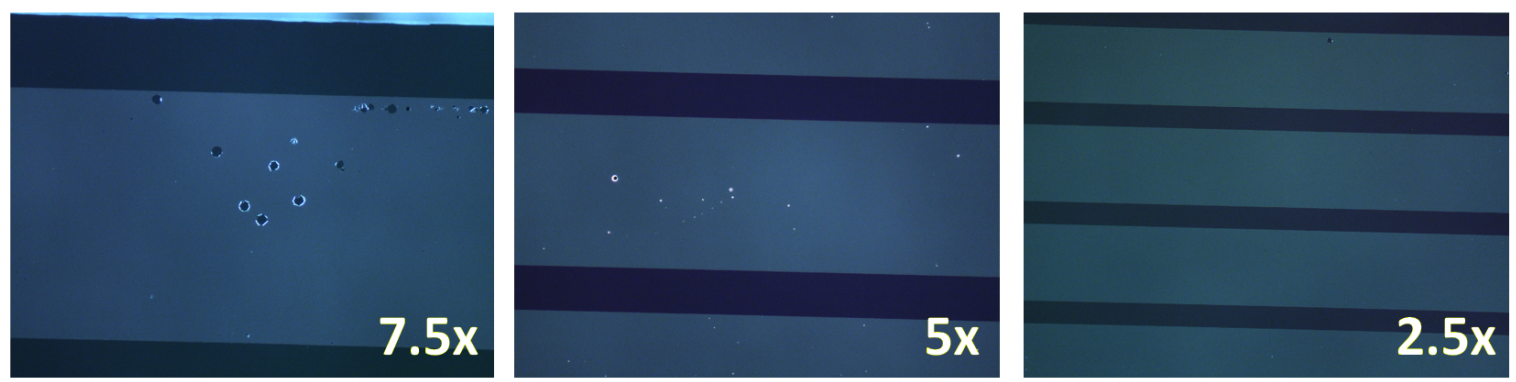

Figure 12: Microscope images of the DMSO and SC-1 treated Ir single-layer SPO 574-10. From left to right: top center, middle center, and bottom center. 
The degree of damage from SC-1 exposure appeared to fluctuate across other samples comparable to SPO 57410. Figure 13 shows samples that were chemically treated at either DTU Nanolab or at cosine Research BV. Contrary to the above results, the SC-1 bath caused extensive coating damage on these samples such as pinholes spanning a few $\mu \mathrm{m}$ in diameter, as well as cracks and delamination across the entire sample surface.
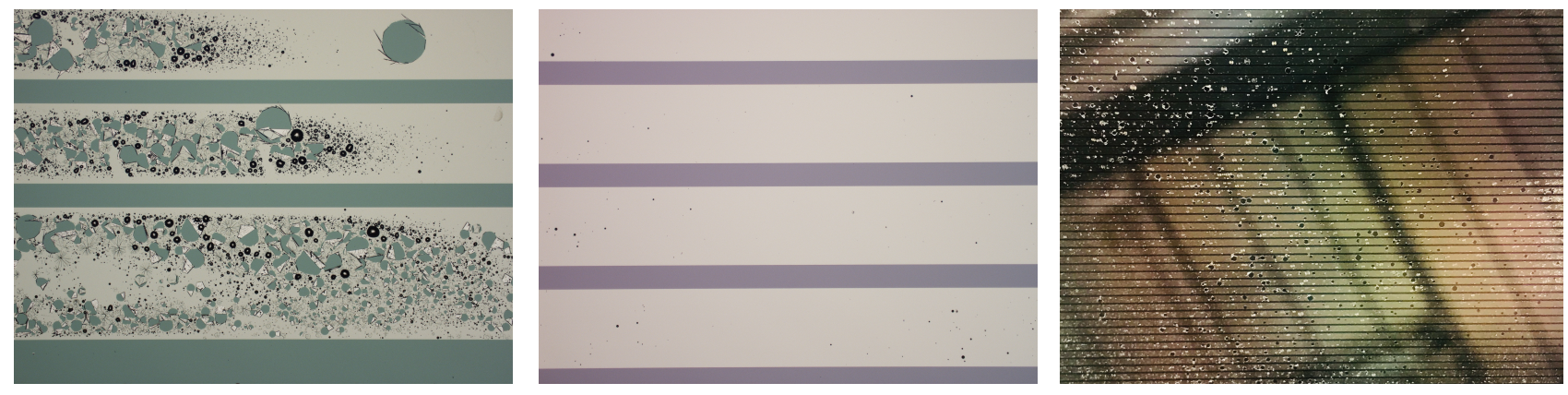

Figure 13: Comparison of SPO samples coated with Ir at DTU Space after DMSO and SC-1 treatment. The samples were not plasma cleaned prior to coating. Right and center: Different degrees of damage on the same sample after DMSO and SC-1 treatment at DTU Nanolab (sample edge and center at 2.5× magnification, respectively). Left: Coating damage across the entire sample surface following DMSO and SC-1 treatment performed by cosine Research BV.

This observed coating damage is not attributed to incompatibility with the thin film itself or to the DMSO treatment. Since the SC-1 is designed to dissolve organic material, it was suggested that the damage was caused by the solution dissolving scattered substrate contamination trapped under the coating ${ }^{19}$. This was supported by the similarity of contamination patterns seen in AFM, compared to the patterns of coating damage.

In order to test this idea, two witness samples, of which one substrate was not plasma cleaned (si6522) while the other was plasma cleaned using the PA system at DTU Nanolab (si6541), were coated with $10 \mathrm{~nm}$ Ir at DTU Space. The samples were exposed to DMSO and SC-1 at DTU Nanolab.
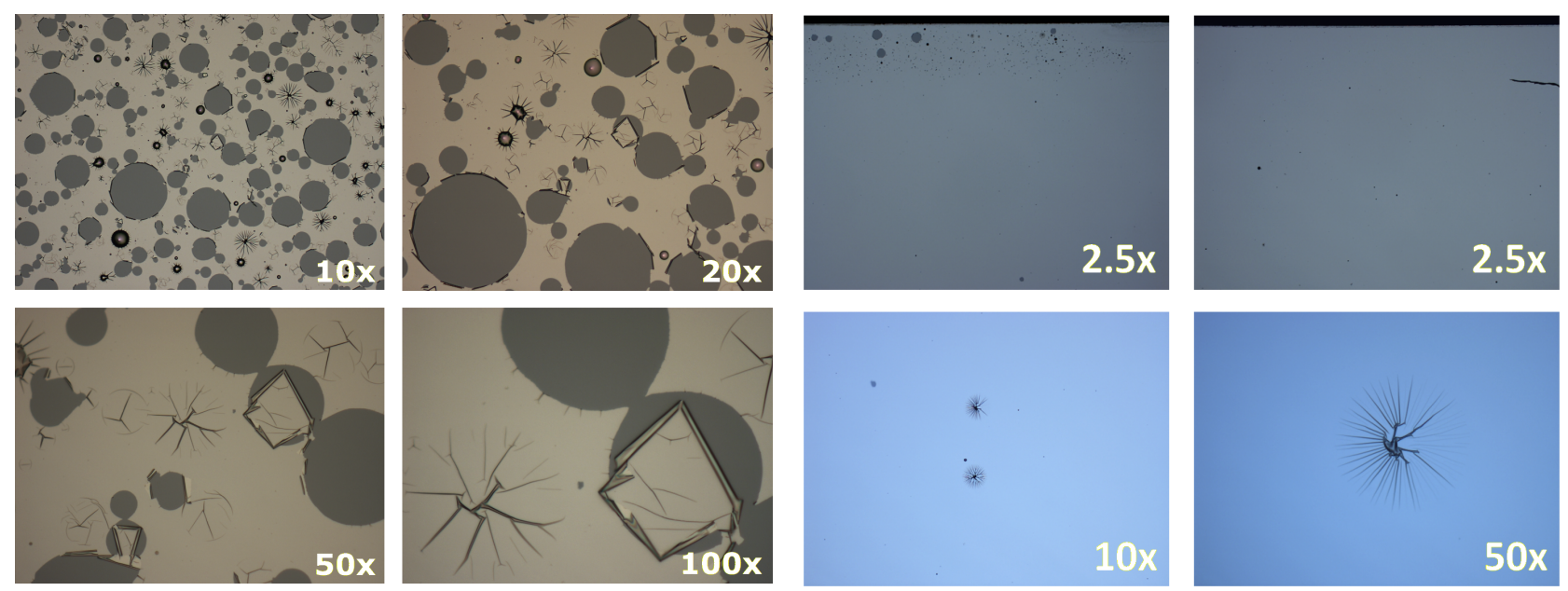

Figure 14: Microscope images of Ir single-layer witness samples comparing the effects of pre-coating plasma cleaning after DMSO and SC-1 treatment performed at DTU Nanolab. Left: Images taken near the edges of witness sample si6522 (not plasma cleaned). Right: Representative degree of coating damage near the edges of sample si6541 (plasma cleaned).

Figure 14 compares microscope images of the two samples, demonstrating the notable improvement in surface quality when implementing a pre-coating plasma cleaning step. While the coating of si6541 is largely intact, some defects still appear as a result of SC-1 treatment. This is attributed to handling, storage and transportation of the sample from the DTU Nanolab cleanroom to the coating facility at DTU Space which inevitably reintroduces some contamination to the uncoated substrate. 
These results demonstrate that any substrate surface, irrespective of the type and prior condition, should be assumed contaminated prior to coating. The different levels of surface contamination are likely caused by transport and handling of samples, as well as remnants from photoresist development. A pre-coating plasma cleaning procedure of SPOs, including prior to sample mounting and in-situ using the ISE, was therefore established as a requisite for compatibility with the $\mathrm{SC}-1$ procedure to preserve the telescope performance.

\subsection{Chemistry robustness of thin films prepared at the Athena-dedicated coating facility}

Assuming the in-situ plasma cleaning eliminates most substrate contamination prior to coating, thin films produced at the Athena-dedicated coating facility enabled a study on the isolated effect of the SC-1 treatment on representative thin films.

A set of photoresist patterned SPO samples were coated with $10 \mathrm{~nm}$ Ir at the Athena-dedicated coating facility. The samples were plasma cleaned in-situ with the ISE prior to coating. DMSO and SC-1 treatment of SPO 766-13 was carried out by cosine Research BV.

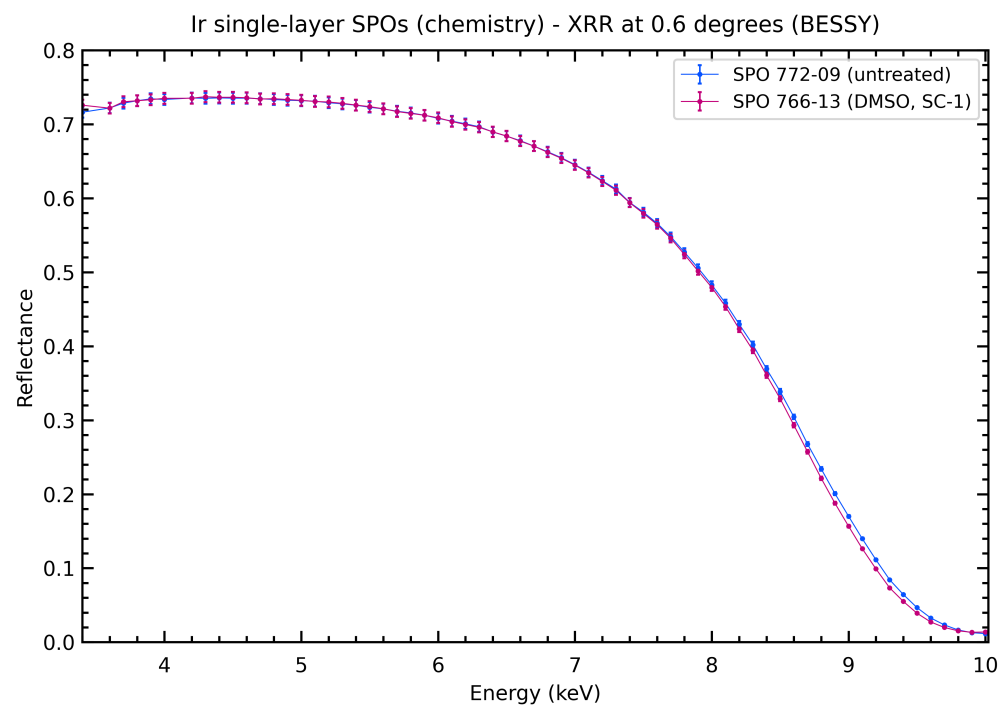

Figure 15: XRR at 0.6 degrees measured at the laboratory of PTB at BESSY II comparing Ir single-layer coated SPO 772-09 (no chemistry, untreated) and SPO 766-13 (DMSO and SC-1).

The samples were measured at the laboratory of PTB at BESSY II with the beam shaping slit set to $0.8 \times 0.6$ $\mathrm{mm}^{2}$. Figure 15 demonstrates agreement between measurements of the untreated reference (SPO 772-09) and the DMSO and SC-1 treated sample (SPO 766-13). This result indicates that the SC-1 has no immediate effect on Ir-only films. The long-term stability still needs to be demonstrated but according to the results of section 3.2 , no performance degradation is expected.

To evaluate the robustness of $\mathrm{Ir} / \mathrm{SiC}$ bilayers to DMSO and SC-1 treatment, a set of unpatterned SPO plates was coated with aimed $\mathrm{Ir}$ and $\mathrm{SiC}$ film thicknesses of $10 \mathrm{~nm}$ and $4 \mathrm{~nm}$, representative of the optimized Athena coating design. The SPO plates were plasma cleaned with the ISE prior to coating.

SPO 396-12 and SPO 816-15 were selected for DMSO and SC-1 treatment. The wet chemistry procedures were carried out by cosine Research BV the same day as the samples were retrieved from the coating chamber and exposed to the atmosphere. SPO 440-06 and SPO 667-12 were kept as untreated reference samples to SPO 396-12 and SPO 816-15, respectively. 
No coating damage was observed by visual inspection following chemistry treatment. The two reference and chemistry treated SPO pairs were measured with 0.6 degree XRR at BESSY as shown in figure 16. Note that the samples were measured during different campaigns and the beam shaping slits were different: $0.8 \times 0.7 \mathrm{~mm}^{2}$ (SPO 440-06, SPO 396-12) and $0.8 \times 1.5 \mathrm{~mm}^{2}$ (SPO 816-15, SPO 667-12).

The simulated reflectance models represent an Ir single-layer $(10 \mathrm{~nm})$ and an $\mathrm{Ir} / \mathrm{SiC}$ bilayer $(10 \mathrm{~nm} / 4 \mathrm{~nm})$, each assuming roughnesses of $0.45 \mathrm{~nm}$ across all interfaces. Both XRR measurements of the untreated samples are in agreement with the $\mathrm{Ir} / \mathrm{SiC}$ bilayer design. It appears, however, that the DMSO and SC-1 treated samples have suffered removal of the $\mathrm{SiC}$ overlayer to different extents. Based on the results presented in the previous section, this is not believed to be an effect of DMSO treatment. Due to the inconsistency in removal, the observed degradation must be due to the SC-1 treatment, rather than material incompatibility.

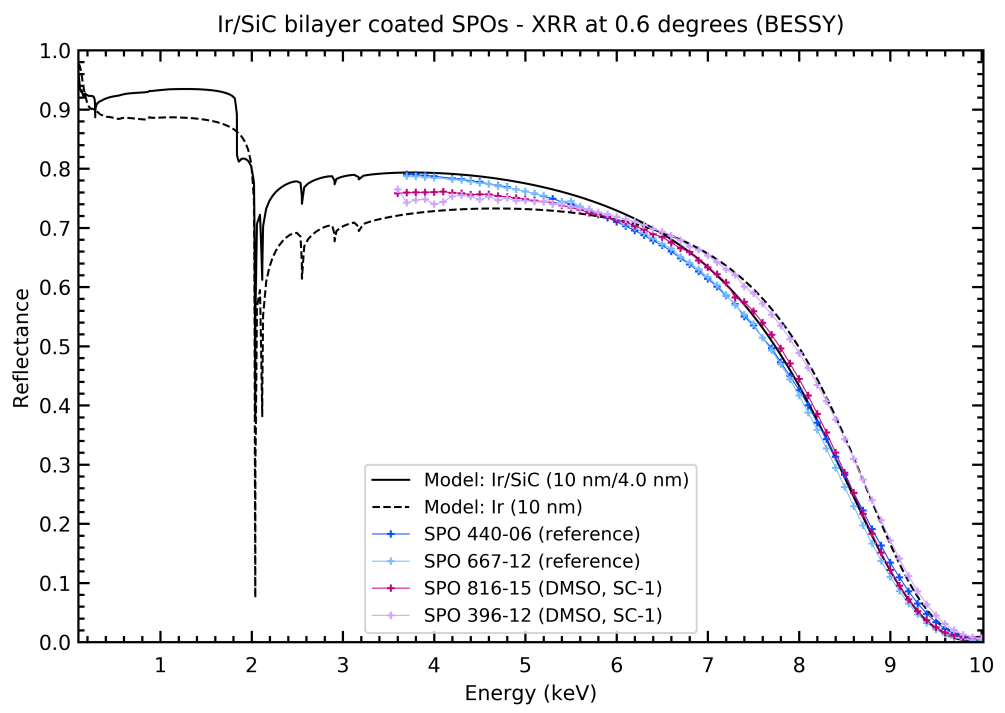

Figure 16: XRR at 0.6 degrees measured at BESSY comparing two pairs of untreated $\mathrm{Ir} / \mathrm{SiC}$ bilayer reference samples (SPO 440-06 and SPO 667-12) to the DMSO and SC-1 treated samples (SPO 396-12 and SPO 816-15). Simulated reflectance curves for Ir single-layer $(10 \mathrm{~nm})$ and $\mathrm{Ir} / \mathrm{SiC}$ bilayer $(10 \mathrm{~nm} / 4 \mathrm{~nm})$ models are overplotted.

It is crucial for a stable telescope performance to understand how the process parameters impact the mirror coating properties. With the observed inconsistent removal of $\mathrm{SiC}$, a thorough investigation of the SC-1 procedure is recommended in order to mitigate risk factors to the Athena performance, independent of the choice of low- $\mathrm{Z}$ overlayer material ( $\mathrm{SiC}, \mathrm{B}_{4} \mathrm{C}$ or $\mathrm{C}$ ). A new, fully automated wetbench is being commissioned at cosine Research $\mathrm{BV}$ which will improve the monitoring of the SC-1 bath concentration.

\subsection{Thermal robustness of $\mathrm{Ir} / \mathrm{SiC}$ bilayer thin films prepared at DTU Space}

The first test of robustness to the SPO post-stacking annealing of Ir/SiC bilayers was performed using thin films prepared at DTU Space. The samples were plasma cleaned with the PA system prior to coating.

Two Ir/SiC bilayer witness samples were characterized prior to any post-coating treatment at $8.048 \mathrm{keV}$ using the XRD SmartLab at DTU Nanolab and at $1.487 \mathrm{keV}$ with LEXR. The measurements and annealing were carried out 3 months after coating.

Figure 17 shows reference XRR measurements of the untreated witness samples si7017 and si7021. The two samples are comparable aside from differences in the Kiessig fringes at higher angles. This could be an effect of coating non-uniformity. The larger sampling step size above 8 degrees in LEXR data is due to a wrong step size setting in the measurement script. The data is however still sufficient to capture the features of the reflectance curve. 

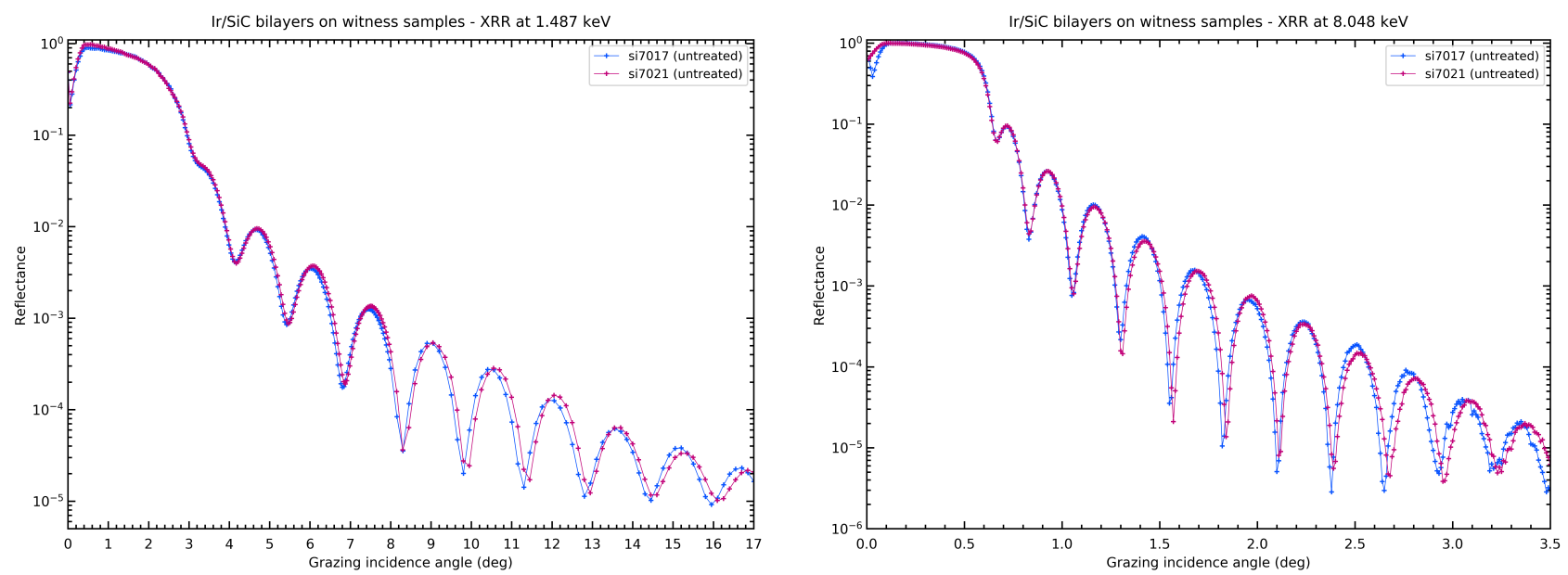

Figure 17: XRR measurements at $1.487 \mathrm{keV}$ (LEXR, left) and $8.048 \mathrm{keV}$ (XRD, right) of Ir/SiC bilayer samples si7017 and si7021 coated at DTU Space. Both samples were untreated.

Witness sample si7021 was heated to $200{ }^{\circ} \mathrm{C}$ for 50 hours at DTU Space. Immediately following annealing, the untreated reference and the annealed sample were measured in LEXR. $8.048 \mathrm{keV}$ measurements were performed in the XRD SmartLab after the samples had been removed from the LEXR vacuum chamber. These measurements indicate negligible effects on the $\mathrm{Ir} / \mathrm{SiC}$ bilayer coating after the standard annealing procedure.

Best fit parameters to the XRR measurements before and after annealing are presented in table 4. For the $8.048 \mathrm{keV}$ measurements, the $\mathrm{SiC}$ thickness was fixed to the value obtained from $1.487 \mathrm{keV}$ data, and the $\mathrm{SiC}$ roughness was coupled to the Ir roughness.

For the fits to $1.487 \mathrm{keV}$ data, the $\mathrm{SiC}$ roughnesses converge to high values of $0.93-1.31 \mathrm{~nm}$. However, this model parameter does not appear to be well-constrained from these measurements, and further XRR and AFM measurements are needed to evaluate the $\mathrm{Ir} / \mathrm{SiC}$ bilayer surface roughness.
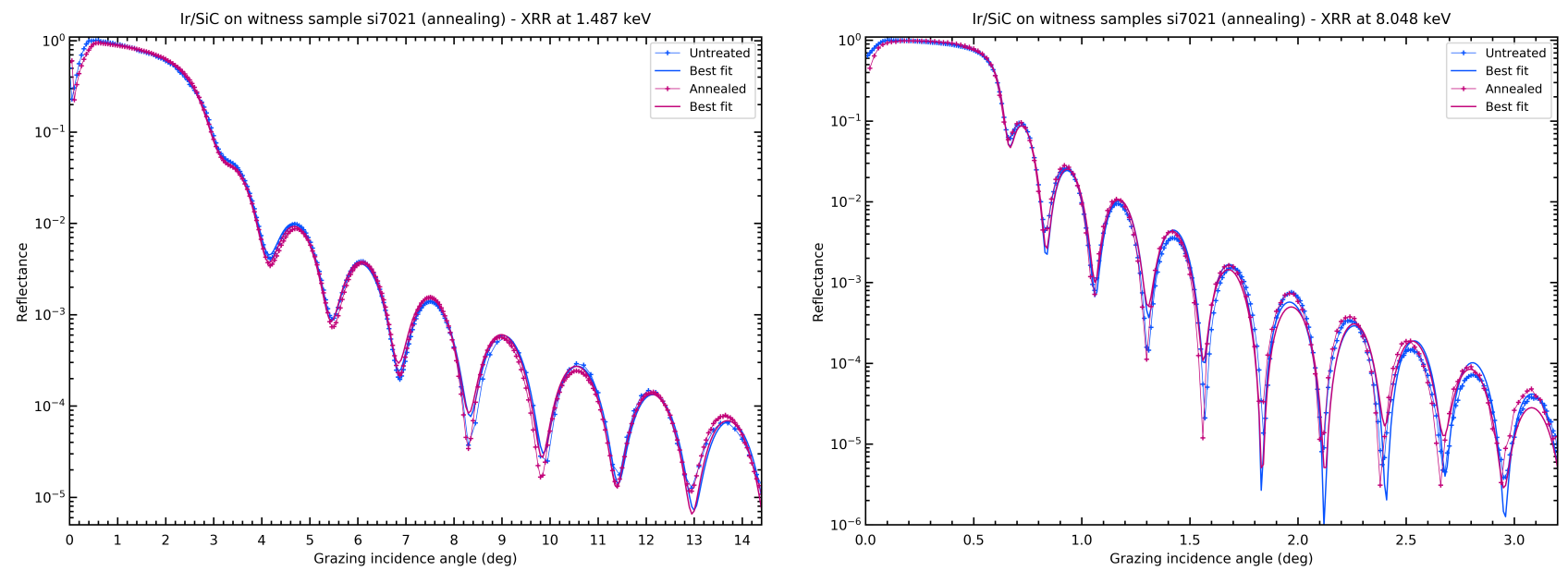

Figure 18: XRR measurements at $1.487 \mathrm{keV}$ (left) and $8.048 \mathrm{keV}$ (right) of Ir/SiC bilayer sample si7021 before and after annealing at $200{ }^{\circ} \mathrm{C}$ for 50 hours. 
Table 4: Best fit parameters for Ir/SiC bilayer coated witness sample si7021 (before and after annealing) measured at $1.487 \mathrm{keV}$ (LEXR) and at $8.048 \mathrm{keV}$ (XRD). ${ }^{a}$ denotes a fixed parameter. Parameters marked with ${ }^{b}$ or $^{c}$ were fitted as coupled parameters. The $\chi^{2}$ is weighted by the reflectance.

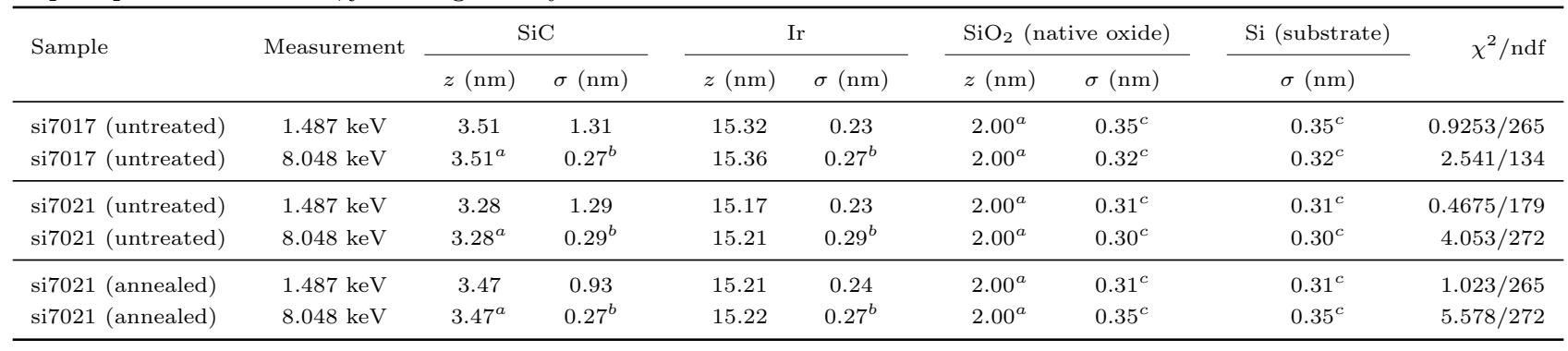

BESSY energy spectra of the untreated reference si7017 and annealed si7021 witness samples measured at 0.4, 0.6 and 1.0 degree grazing incidence angles are presented in figure 19. The samples were measured using a beam size setting of $0.35 \times 1.5 \mathrm{~mm}^{2}$.

These measurements are in agreement at 0.4 and 1.0 degrees. The discrepancy at 0.6 degrees must therefore be the result of sample misalignment. This is demonstrated in figure 19 (right) where the 0.6 degree measurements are shown with models simulated from the fit parameters obtained from $1.487 \mathrm{keV}$ data. The reference witness sample si7017 is consistent with a model at a grazing incidence of 0.61 degrees, indicating a 10 millidegree offset to this sample alignment only. The annealed sample si7021 is in agreement with its derived model at 0.60 degrees, as well as the si7017 model at 0.60 degrees.

The presented results demonstrate that the $\mathrm{Ir} / \mathrm{SiC}$ bilayer coated at DTU Space is robust to the established post-stacking annealing procedure within measurement limitations.
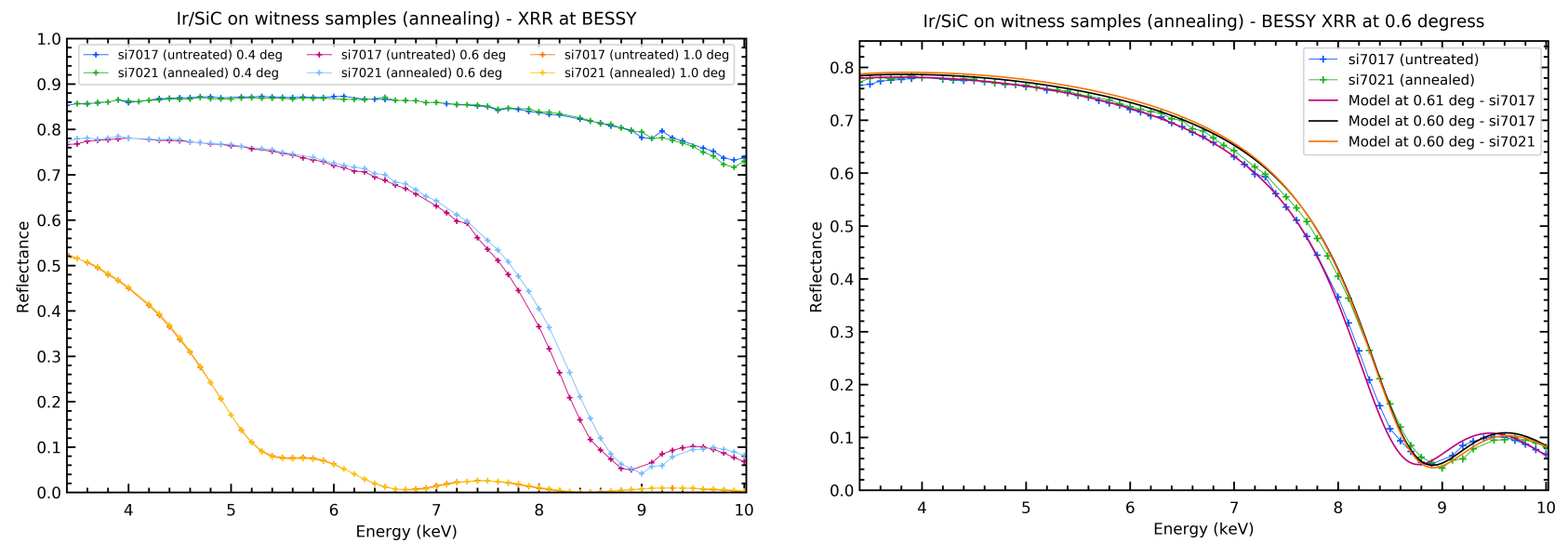

Figure 19: Left: XRR measurements performed at the laboratory of PTB at BESSY II at $0.4,0.6$ and 1.0 degrees comparing the $\mathrm{Ir} / \mathrm{SiC}$ bilayer witness samples si7017 (untreated reference) and si7021 (annealed). Right: Measurements at 0.6 degrees of the $\mathrm{Ir} / \mathrm{SiC}$ bilayer witness samples si7017 (untreated reference) and si7021 (annealed). Models simulated from fits to $1.487 \mathrm{keV}$ data are overplotted to demonstrate the angular offset in si7017 data. 


\section{SUMMARY}

The SPO stack production requires a wet chemical treatment of coated mirror plates in two steps to perform photolithographic lift-off and surface cleaning, respectively. Establishing compatibility of the candidate thin film designs with the chemical process steps is therefore crucial for the success of the Athena telescope.

The investigation of Ir and $\mathrm{Ir} / \mathrm{SiC}$ thin films produced in the DTU Space coating chamber suggests that the coatings are preserved after exposure to DMSO. These results demonstrate that the photolithographic lift-off process step does not damage the coating, nor does it affect any underlying substrate contamination, even if the samples are not plasma cleaned prior to film deposition.

Exposing Ir single-layer samples to SC-1 has established the importance of thorough substrate plasma cleaning to preserve the thin film, leading to the implementation of standard pre-coating plasma cleaning procedures.

Ir-only thin films produced at both DTU Space and at the new Athena-dedicated coating facility appear robust to the current SC-1 procedure. The low- $\mathrm{Z}$ overlayer may be compromised due to the process parameters of the $\mathrm{SC}-1$ exposure, as preliminary results on $\mathrm{Ir} / \mathrm{SiC}$ bilayers indicate. With the installation of an automatized wet bench at cosine Research BV, the characterization of chemistry-treated $\mathrm{Ir}$ and $\mathrm{Ir} / \mathrm{SiC}$ thin films produced at the Athena-dedicated coating facility will proceed in order to establish the impact of SC-1.

Post-stacking annealing of coated SPO stacks is considered as a process requirement to improve the bond strength between stacked plates. First results on annealing of $\mathrm{Ir} / \mathrm{SiC}$ bilayers produced at DTU Space indicate that these thin films are robust to annealing at $200{ }^{\circ} \mathrm{C}$ for 50 hours. A follow-up qualification and long-term stability assessment of annealed samples produced at the Athena-dedicated coating facility is in progress.

\section{ACKNOWLEDGEMENT}

This activity has been funded by the European Space Agency under contract 4000102248/10/NL/PM.

\section{REFERENCES}

[1] Nandra, K., Barret, D., Barcons, X., et al., "The Hot and Energetic Universe: A White Paper presenting the science theme motivating the Athena+ mission," astro-ph.HE arXiv:1306.2307 (2013).

[2] Beijersbergen, M., Kraft, S., Gunther, R., et al., "Silicon pore optics: novel lightweight high-resolution X-ray optics developed for XEUS," Proceedings of SPIE 5488 (2004).

[3] Bavdaz, M., Wille, E., Ayre, M., et al., "Optics developments for ATHENA," Proceedings of SPIE 11119 (2019).

[4] Collon, M., Vacanti, G., Barriere, N., et al., "Status of the silicon pore optics technology," Proceedings of SPIE 11119 (2019).

[5] Ferreira, D. D. M., Massahi, S., Christensen, F. E., et al., "Design, development, and performance of X-ray mirror coatings for the ATHENA mission," Proceedings of SPIE 10399 (2017).

[6] Ferreira, D. D. M., Svendsen, S., Massahi, S., et al., "Performance and stability of mirror coatings for the ATHENA mission," Proceedings of SPIE 10699 (2018).

[7] Ferreira, D. D. M., Christensen, F. E., Jakobsen, A. C., Westergaard, N. J. S., and Shortt, B., "ATHENA coating optimization," Proceedings of SPIE 8443 (2012).

[8] Ferreira, D. D. M., Christensen, F. E., Jakobsen, A. C., et al., "Coating optimization for the ATHENA+ mission," Proceedings of SPIE $\mathbf{8 8 6 1}$ (2013).

[9] Ferreira, D. D. M., Massahi, S., Svendsen, S., Henriksen, P. L., Christensen, F. E., Gellert, N., Vu, L. M., 'S Jegers, A., and Shortt, B., "X-ray mirror coatings for ATHENA: Development status and performance," Proceedings of SPIE 11444 (2020).

[10] A. C. Jakobsen and D. D. M. Ferreira and F. E. Christensen and B. Shortt and M. Collon, "Preliminary coating design and coating developments for athena," Proceedings of SPIE 8147 (2011).

[11] Ferreira, D. D. M., Jakobsen, A. C., Christensen, F. E., et al., "Development and characterization of coatings on Silicon Pore Optics substrates for the ATHENA mission," Proceedings of SPIE 8443 (2012).

[12] Massahi, S., Girou, D., Ferreira, D. D. M., et al., "Investigation of photolithography process on SPOs for the ATHENA mission," Proceedings of SPIE 9603 (2015). 
[13] Ferreira, D. D. M., Jakobsen, A. C., Massahi, S., et al., "X-ray mirror development and testing for the athena mission," Proceedings of SPIE 9005 (2016).

[14] Massahi, S., Christensen, F. E., Ferreira, D. D. M., et al., "The effect of nitrogen incorporation in boron carbide and iridium thin films," Proceedings of SPIE 10699 (2018).

[15] Massahi, S., Industrialization of the mirror plate coatings for the ATHENA mission, PhD thesis, Technical University of Denmark (2019).

[16] Svendsen, S., Massahi, S., Ferreira, D., et al., "Performance and time stability of Ir/SiC X-ray mirror coatings for ATHENA," Proceedings of SPIE 11119 (2019).

[17] Jafari, A., Ferreira, D. D. M., Kadkhodazadeh, S., Massahi, S., Svendsen, S., Vu, L. M., Henriksen, P. L., Balogh, Z. M., Krumrey, M., Cibik, L., Christensen, F. E., Shortt, B., and Kasama, T., "Long-term performance and durability of ir $/ \mathrm{b}_{4} \mathrm{c}$ multilayer x-ray mirrors: focusing on composition, structure, and reflectivity properties," Journal of Astronomical Telescopes, Instruments, and Systems 6(3) (2020).

[18] Landgraf, B., Girou, D., Collon, M. J., et al., "Environmental testing of the ATHENA mirror modules," Proceedings of SPIE 10399 (2017).

[19] Girou, D., Massahi, S., Ferreira, D., et al., "Plasma etching for the compatibility of thin film metallic coatings and direct bonding of silicon pore optics," Journal of Applied Physics 128(9) (2020).

[20] Windt, D. L., "'IMD - Software for modeling the optical properties of multilayer films"," Computers in Physics 12(360) (1998).

[21] Henriksen, P. L., Christensen, F. E., Massahi, S., et al., "LEXR: A low-energy X-ray reflectometer for characterization of ATHENA mirror coatings," Proceedings of SPIE 11119 (2019).

[22] Henriksen, P. L., Christensen, F. E., Massahi, S., et al., "Qualification and performance of the Low-Energy X-ray Reflectometer (LEXR)," Proceedings of SPIE 11444 (2020).

[23] Krumrey, M. and Ulm, G., "High-accuracy detector calibration at the PTB four-crystal monochromator beamline," Nucl. Instr. and Meth. A 467-468 (2001).

[24] Necas, D. and Klapetek, P., "Gwyddion: an open-source software for SPM data analysis," Central European Journal of Physics 10 (2012).

[25] Windt, D. L., "TOPO - Surface topography analysis, version 2.05," (2000). 